\title{
A dual luciferase assay for evaluation of skin sensitizing potential of medical devices
}

\author{
Elisabeth Mertl ${ }^{1}$ - Elisabeth Riegel ${ }^{2}$. Nicole Glück ${ }^{2}$. Gabriele Ettenberger-Bornberg ${ }^{1}$ - Grace Lin ${ }^{1}$. Sabrina Auer ${ }^{1}$. \\ Magdalena Haller ${ }^{1} \cdot$ Angelika Wlodarczyk $^{1}$ - Christoph Steurer ${ }^{2} \cdot$ Christian Kirchnawy $^{1} \cdot$ Thomas Czerny $^{2}$ (I)
}

Received: 20 March 2019 / Accepted: 2 July 2019 / Published online: 30 July 2019

(C) The Author(s) 2019

\begin{abstract}
According to standing regulations animal tests are still state of the art for the evaluation of the sensitization potential of medical devices. The aim of our study was to develop an in vitro method that can be used for testing of extracts of medical devices. The novel MDA-ARE assay is a cell based reporter gene assay focused on the ARE-Nrf2 pathway, which is involved in the dermal sensitization process. Optimization of the reporter construct and the cell line resulted in an improvement of the detection limit and a reduction of the incubation time to $6 \mathrm{~h}$, which lowers cytotoxic side effects of the extracts on the cells. Using the assay, 21 out of 22 pure chemicals were identified correctly as skin sensitizers or non-sensitizers. All sensitizers could be detected at far lower concentrations compared to the local lymph node assay, the state-of-the-art animal test. To evaluate the assay's suitability for the testing of medical devices, medical grade silicone containing $0.1 \%$ of known skin sensitizers was prepared as positive controls and extracts of these positive controls were tested in comparison to extracts from pure silicone samples. All silicone samples were correctly and reproducibly identified as sensitizing or non-sensitizing demonstrating that the MDA-ARE assay is a sensitive and reliable tool for the detection of skin sensitizers in extracts of medical devices. The developed and validated test protocol was used for medical device extracts and showed its applicability for real samples and thus can contribute to reduce or even to replace the need for animal tests.
\end{abstract}

Keywords In vitro $\cdot$ Skin sensitization $\cdot$ Medical devices $\cdot$ Luciferase $\cdot$ ARE $\cdot$ Nrf2

\section{Introduction}

Humans are exposed to a variety of toxic substances, many of which can lead to irritating and sensitizing reactions. In particular, medical devices like implants exhibit long-term contact to human tissues. In order to guarantee safety for the

Elisabeth Mertl and Elisabeth Riegel have contributed equally to this work.

Electronic supplementary material The online version of this article (https://doi.org/10.1007/s11033-019-04964-8) contains supplementary material, which is available to authorized users.

Thomas Czerny

thomas.czerny@fh-campuswien.ac.at

1 OFI - Austrian Research Institute for Chemistry and Technology, Brehmstraße 14 A, 1110 Vienna, Austria

2 Department of Applied Life Sciences, University of Applied Sciences, FH Campus Wien, Helmut-Qualtinger-Gasse 2, 1030 Vienna, Austria end-users of medical devices, products have to be tested for adverse reactions on the skin. Equipment that gets in contact with the patients' skin has to be assessed at least for cytotoxicity, irritation and sensitization potential [1]. According to international standards (ISO 10993), only cytotoxicity can be evaluated with in vitro methods, while the assessment of an irritating or sensitizing potential of medical devices is still based on animal tests [2,3]. Substitution of these in vivo tests for assessment of skin irritation and skin sensitization are driven by the Organisation for Economic Co-operation and Development (OECD) and the European Union Reference Laboratory for alternatives for animal testing (EURL ECVAM) [4-6]. The aim of this work was focused on the development and validation of a suitable in vitro testing method to estimate the skin sensitization potential of medical device extracts. Skin sensitization is defined as a cutaneous reaction triggered by immunological responses to a substance, which can manifest in the form of allergic contact dermatitis [7, 8]. 
First attempts for predicting sensitization of chemicals as well as of medical devices were based on guinea pig tests [9, 10] and later on the mouse local lymph node assay (LLNA) [8]. Socio-political pressure focused on the 3R principle [11] has led to various attempts in the development of alternative methods [12-14]. In 2015 the first methods became accepted as OECD guidelines as validated in vitro assays to assess skin sensitization (DPRA and KeratinoSens) [4, 5]. In 2016 the h-Clat assay was added [6]. However, these assays have only been validated for pure chemicals, whereas extracts of medical devices are still undergoing animal testing [15].

Extracts of medical devices show different challenges for in vitro testing [16]. On the one hand, matrix effects might disturb the tests, on the other hand cytotoxic substances leaching from the medical device can interfere with cell culture assays. Furthermore, medical devices should be extracted with polar and non-polar solvents. The use of non-polar solvents in cell culture assays bears risk of cytotoxicity if they are not diluted, however a dilution reduces the chance of detecting sensitizers at low concentrations. Therefore, most in vitro tests focus on the assessment of pure chemicals and so far no in vitro test for detection of the skin sensitizing potential of extracts of medical devices has been established.

However, in vitro assays are not the only available information source for the evaluation of the safety of substances but form part of a weight of evidence approach in an integrated testing strategy (ITS) [17]. As sensitization itself is the result of various complex events, many researchers believe that no single test alone can predict all human sensitizers [15]. While animal tests screen the whole sensitization process, alternative in vitro testing methods are focused on various different key events of the adverse outcome pathway (AOP) starting with an initial binding of haptens to proteins leading to activation of keratinocytes and dendritic cells and proliferation of T-cells and finally the manifestation as allergic contact dermatitis [18]. In this context, approaches combining various in vitro, in chemico and in silico tests have been established [19]. Following procedures of integrated approaches to testing and assessment (IATA), prediction models are already used in the evaluation of chemicals in the cosmetic industry and in the EU regulation for registration, evaluation, authorization and restriction of chemicals (REACH) [20]. Through IATA, already available data, together with newly generated results from different tests and computer based models (for structural similarities or mechanistic categories), is assessed for the characterization of chemical hazards [21-25].

Although risk assessment through prediction models has already gained wide acceptance, assessment of sensitization of complex formulations of medical devices is still a more difficult challenge. Especially impurities, degradation and decomposition products which form part of the final product, but were not intentionally added during manufacturing, cannot be identified easily. These substances might influence the toxicity of the product, which makes in silico hazard assessment challenging $[26,27]$. The main advantage of in vivo and in vitro tests is that no information about the composition is necessary for risk assessment.

The antioxidant response pathway was found to be a good sensor for the prediction of skin sensitizing potential [28]. The pathway activity is upregulated in skin models as well as in various keratinocyte cell lines in a quantitative way after treatment with skin sensitizing chemicals [17, 29] and was successfully used to create the KeratinoSens cell culture assay which has been published as an OECD testing guideline for pure substances [5]. In non-activated cells, the cytoplasmic protein Keap1 (Kelch-like ECH-associated protein 1) usually binds to Nrf2 (nuclear erythroid 2-related factor 2) and leads to its rapid degradation via ubiquitination. After reaction of thiol-groups with chemicals, Keap1 undergoes conformational changes and dissociates from Nrf2, leading to its accumulation and nuclear translocation. In the nucleus Nrf2 heterodimerizes with small Maf proteins and binds to antioxidant response elements (ARE) in promoter regions of cytoprotective and antioxidant genes, resulting in activation of these target genes (reviewed in [30]).

We used the antioxidant pathway to detect skin sensitizers as pure substances and in complex formulations. The major goal was to enable testing of medical device extracts and provide an alternative to animal testing.

\section{Materials and methods}

\section{Test materials}

Sensitizing chemicals were benzylideneacetone (CAS 12257-6, Sigma), oxazolone (15646-46-5, Sigma), 1,4-benzoquinone (CAS 106-51-4, Sigma), 2,4-dinitrochlorobenzene (CAS 97-00-7, Sigma), 4-nitrobenzylbromide (CAS 10011-8, Sigma), glyoxal (CAS 107-22-2, Sigma), methyldibromoglutaronitrile (CAS 35691-65-7, Sigma), cinnamic aldehyde (CAS 104-55-2, SAFC), isoeugenol (CAS 97-541, Sigma), ethylene glycol dimethacrylate (CAS 97-90-5, Sigma), 2-mercaptobenzothiazole (CAS 149-30-4, Sigma), tetramethyl thiuram disulphide (CAS 137-26-8, Sigma), eugenol (CAS 97-53-0, Sigma), cinnamic alcohol (CAS 104-54-1, Sigma) and non-sensitizing substances include sodium dodecyl sulfate (CAS 151-21-3, Carl Roth), salicylic acid (CAS 69-72-7, Carl Roth), glycerol (CAS 56-81-5, Carl Roth), lactic acid (CAS 50-21-5, Carl Roth), methyl salicylate (CAS 119-36-8, Thermofisher), diethylphthalate (CAS 84-66-2, Thermofisher), sulphanilamide (CAS 64-741, Thermofisher), chlorobenzene (CAS 108-90-7, VWR) and isopropanol (67-63-0, CHEM-LAB). 
Tested chemicals were chosen according to the "Performance Standards for Assessment of Proposed Similar or Modified In Vitro Skin Sensitisation ARE-NRF2 Luciferase Test Methods" published by the OECD and according to Casati et al. [5, 31].

For extraction the solvents dimethylsulfoxide (DMSO) (CAS 67-68-5, Merck) and phosphate buffered saline (PBS) (Biochrom, L1825) were used.

\section{Preparation of sensitizing medical device samples}

The silicone Silpuran ${ }^{\circledR} 2400$ was purchased from Wacker Chemie. The silicone consisted of two parts: A and B, whereby part A included a Pt-based catalyst and part B referred to liquid silicone. Pure silicone samples (negative control) were prepared and furthermore, the skin sensitizers cinnamic aldehyde, 1,4-benzoquinone and 2,4-dinitrochlorobenzene were added to the silicone at a concentration of $0.1 \% \mathrm{w} / \mathrm{w}$. Sensitizing chemicals were added to aliquots of component B and mixed with a glass rod. Subsequently, part $A$ and part $B$ (containing sensitizers) were mixed in a ratio of 1:1 and again homogenized with a glass rod. The mixture was then transferred to glass test tube and cured overnight. After breaking the glass, the silicone containing skin sensitizers could be recovered and was cut into smaller pieces.

\section{Extraction of samples and positive control}

All samples were extracted with DMSO and PBS using a surface volume ratio according to ISO 10993-12:2012 [32]. $3 \mathrm{~cm}^{2} / \mathrm{mL}$ were applied to solid samples with a defined surface that were thicker than $0.5 \mathrm{~mm}$. Samples thinner than $0.5 \mathrm{~mm}$ were extracted with $6 \mathrm{~cm}^{2} / \mathrm{mL}$ and textiles like sutures were extracted using $0.2 \mathrm{~g} / \mathrm{mL}$. Extraction was performed at $37 \pm 1^{\circ} \mathrm{C}$ for $72 \pm 2 \mathrm{~h}$ with agitation. DMSO extracts were diluted 1:100 in PBS and PBS extracts 1:100 in PBS $+1 \%$ DMSO. Further dilution steps were made. Extracts and dilutions were applied to the cells within 7 days. Samples were stored at $5{ }^{\circ} \mathrm{C}$ until testing. As a positive control cinnamic aldehyde $(32 \mu \mathrm{M})$ was added to the extracts to detect false negative results derived from sample matrices interacting with the testing system.

\section{Sample preparation of pure chemicals}

Chemicals were dissolved in DMSO or PBS 1\% DMSO to a concentration of $200 \mathrm{mM}$. For the highest concentration in the assay $(2 \mathrm{mM})$ the stocks were further diluted 1:100 in PBS or PBS 1\% DMSO resulting in a final DMSO concentration of $1 \%$. Samples were further diluted 1:2 in PBS $1 \%$ DMSO from $2 \mathrm{mM}$ to $0.98 \mu \mathrm{M}$ [5].
Plasmids for reporter optimization and generation of stable cell lines

For optimization of the ARE reporter (ARE sequence, multimerization of ARE binding site, reporter gene) we used transient transfection experiments in HEK293 cells. The pMlucM reporter plasmids were derived from pMlucF backbone [33] by changing the minimal Fos promoter to the artificial minimal promoter (TATAAAATTCTCATTCAG CCGATACCGTCTCACTCT). Four different ARE binding sites were inserted with oligo cloning into the multiple cloning site and mulitmerized up to 12 times. The AREa sequence is derived from the human $A K R I C 2$ gene [34]. For AREb only the consensus core sequence of the AKRIC2 gene was used. For AREc the AP-1 binding site within the $\mathrm{AREb}$ were mutated and AREd is the ARE sequence of mouse Gstal [35]. The constructs for generation of stable cell lines (pGVL8 backbone) in HaCat and MDA-MB486 cells, contained mulitmerized ARE binding sites upstream of the artificial minimal promoter and NanoLuc with protein and mRNA destabilizing sequences (NlucP) [36, 37]. Further the plasmid contained a constitutively expressed firefly luciferase (Fluc) for internal viability measurement, a puromycin resistance gene for selection and piggy bac terminal repeat sequences for genome integration [38]. For details concerning the single plasmids and stable cell lines used in the results section see S1 Table.

\section{Cell culture, transient transfection and generation of stable cell lines}

HEK293 (HEK293 T-Rex purchased from Invitrogen) and HaCat cells (purchased from Cell Line Service) were cultivated in DMEM (PAN-Biotech) supplemented with 10\% (Fetal Calf Serum) FCS (PAN-Biotech) and Penicillin/Streptomycin (HyClone). Medium for MDA-MB486 (purchased from ATCC) was further supplemented with non-essential amino acids (HyClone). Cells were kept at $37{ }^{\circ} \mathrm{C}, 5 \% \mathrm{CO}_{2}$ in a humidified atmosphere. For transient transfection experiments $1 \times 10^{4}$ HEK293 cells per well were seeded into polyethyleneimine (PEI)-coated [39] transparent 96-well plates, incubated for $24 \mathrm{~h}$ at $37^{\circ} \mathrm{C}$, and transfected with TurboFect (Thermo Fisher Scientific) according to the manufacturer's instructions with $10 \mathrm{ng}$ reporter plasmid per well. For the generation of stable cell lines, HaCat or MDA-MB486 cells were transfected with pGVL8 constructs using the piggy bac transposon system [38]. After $48 \mathrm{~h}$ cells were selected with $1.5 \mu \mathrm{M}$ puromycin added to the normal growth medium. Positive clones were picked after puromycin selection. Clones were tested for induction with $100 \mu \mathrm{M}$ benzylideneacetone and selected for low basal NlucP levels and high induction rate. For more information on stable cell lines see S1 Table. 


\section{Luciferase and viability measurement}

For all experiments except for Table 1, dual luciferase and resazurin measurements were performed as described previously [33]. For single luciferase measurement, only two dispensers $\left(1 \times\right.$ substrate, $\left.1 \times \mathrm{H}_{2} \mathrm{SO}_{4}\right)$ were used, and luciferase activity was measured directly after substrate dispensing.

\section{MDA-ARE assay used to perform experiments shown in Table 1}

$100 \mu \mathrm{L}$ of a cell suspension $\left(10^{5}\right.$ cells $\left./ \mathrm{mL}\right)$ were added to 96 well plates and incubated for $24 \pm 4 \mathrm{~h}$ at $37^{\circ} \mathrm{C}$ in a humidified atmosphere with $5 \% \mathrm{CO}_{2}$. Afterwards, the medium got replaced by $50 \mu \mathrm{L}$ of the sample or dissolved chemicals. The plates were covered with sealing film and incubated for $6 \mathrm{~h}$ at $37{ }^{\circ} \mathrm{C}$ and $5 \% \mathrm{CO}_{2}$.

For measurement of the viability, Steady-Glo ${ }^{\circledR}$ substrate (Promega) was dissolved in the corresponding buffer and further diluted $1: 10$ with $\mathrm{RO}-\mathrm{H}_{2} \mathrm{O}$ to a final concentration of $1.54 \mathrm{mg} / \mathrm{mL}$. $50 \mu \mathrm{L}$ of the Steady-Glo ${ }^{\circledR}$ solution were added to the wells and luminescence measured with a plate reader (Victor ${ }^{3}$, Perkin Elmer).

Afterwards, for measurement of sensitization, the Nano-Glo ${ }^{\circledR}$ Luciferase substrate was diluted 1:50 in the corresponding buffer and further diluted 1:10 in PBS containing $1.5 \%$ EDTA. $50 \mu \mathrm{L}$ of this solution was added to the wells and luminescence measured with a plate reader (Victor ${ }^{3}$, Perkin Elmer).

Fold inductions were calculated as the ratio of the relative light units of the samples to the relative light units of untreated PBS + 1\% DMSO. A fold induction above 2 was counted as significant activation of the ARE-Nrf2 pathway.

\section{Results}

\section{Reporter construction}

The induction of the ARE-Nrf2 pathway was demonstrated to be a reliable indicator of the sensitizing potential of pure chemical substances [28]. To be able to use an ARE reporter approach for testing extracts with only low concentrations of actual sensitizers, but with a large number of other potential cytotoxic components in a complex matrix, the development of a reporter cell line reacting to low concentrations of sensitizers was essential. ARE sequences are present in a large number of cytoprotective genes and the ARE core consensus sequence as binding site for Nrf2 was defined as TMAnnRTGAYnnnGCRwwww [40, 41]. We selected four different ARE sequences (termed AREa, AREb, AREc and AREd) and cloned them upstream of a minimal promoter (TATA box) and firefly luciferase (Fluc) as a reporter gene (Fig. 1a). Using AREb as a model we mulitmerized the sequence up to 12 times and tested the reporter activation after treatment with the potent ARE inducer benzylideneacetone [28]. We found best reporter induction with four-eight AREb sequences

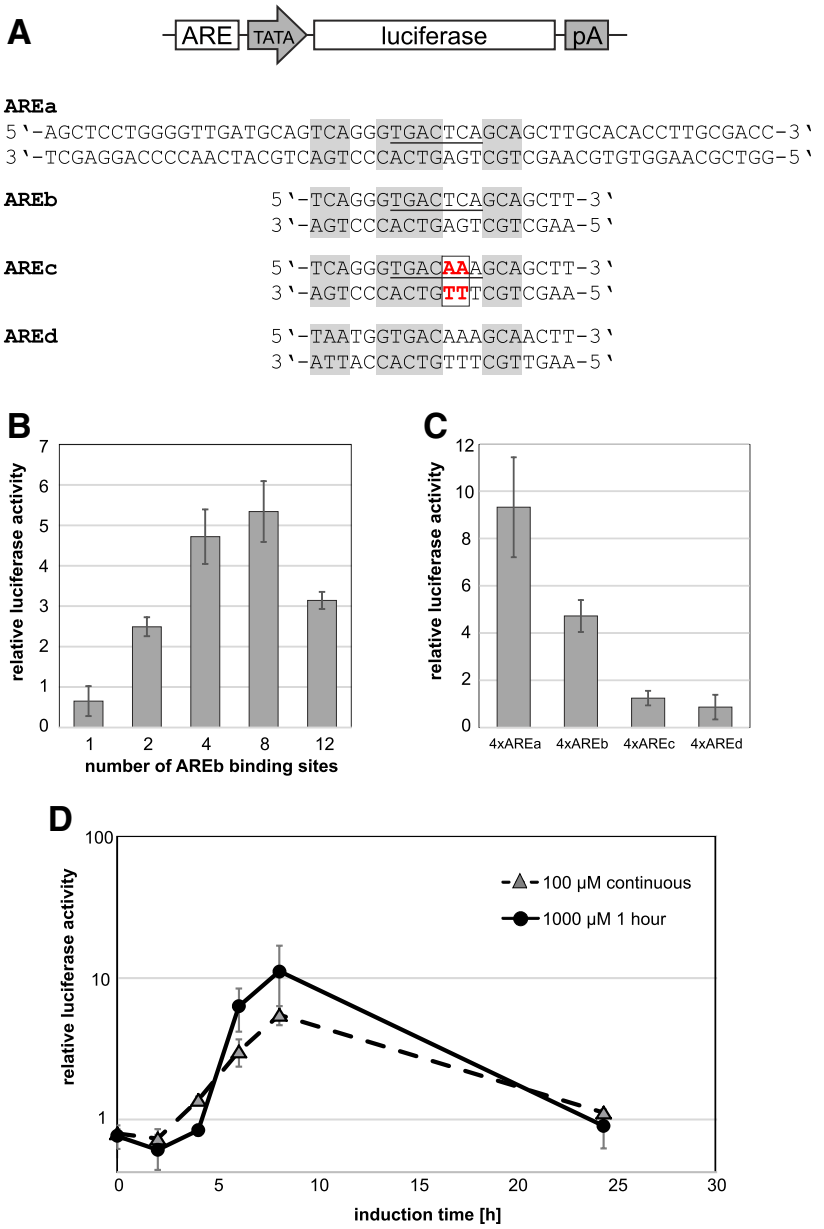

Fig. 1 ARE reporter construct optimization. Four different ARE sequences (AREa, AREb, AREc and AREd) were cloned upstream of a minimal promoter (TATA) and luciferase as reporter gene and a polyadenylation signal (pA) (a). Bases of the ARE consensus sequence are shaded and the overlapping AP1 site is underlined. Mutations of AREc compared to AREb (AP-1 site) are boxed and highlighted in red. For determination of optimal ARE numbers, $\mathrm{AREb}$ was multimerized 1-12 times and the different reporters (pMlucM $1 \times-12 \times$ AREb) were transiently transfected into HEK293 cells (b). For comparison of the different ARE sequences 4 times multimerized reporter constructs (pMlucM $4 \times \mathrm{AREa}, \mathrm{b}, \mathrm{c}, \mathrm{d}$ ) were transiently transfected into HEK293 cells (c) and for kinetics 4 times multimerized NlucP reporter (pGVL8 $4 \times$ AREa) was transiently transfected into HEK293 cells (d). 2 days after transfection cells were induced with $100 \mu \mathrm{M}$ benzylideneacetone in DMEM+10\% FCS for $24 \mathrm{~h}$ before luciferase measurement [b-d (continuous)] or for $1 \mathrm{~h}$ with $1000 \mu \mathrm{M}$ benzylideneactone in DMEM + 10\% FCS and measured after $0,2,4,6,8$ and $24 \mathrm{~h}$ recovery time [d $(1 \mathrm{~h})]$. Y-axis shows relative luciferase activity compared to uninduced control transfections. All values show means of at least 3 independent experiments with 12 replicates per plate. Error bars indicate SEM 
(Fig. 1b). Due to lower background signals, we decided to concentrate on $4 \times$ ARE repeats and compared the different sequences after $24 \mathrm{~h}$ induction with $100 \mu \mathrm{M}$ benzylideneacetone (Fig. 1c). A direct comparison showed that AREa and AREb from human AKR $1 C 2$ worked best (9.3fold $[ \pm 2.1$ SEM (standard error of the mean)] and 4.7-fold $[ \pm 0.8 \mathrm{SEM}]$ induction, respectively). The loss of the AP-1 binding site in the AREc sequence completely abolished reporter activation under the tested conditions and also the AREd sequence from the mouse Gstal gene was not inducible in our system (1.2-fold $[ \pm 0.3 \mathrm{SEM}]$ and 0.9fold $[ \pm 0.5 \mathrm{SEM}]$ induction respectively. We also looked at the pathway kinetics by using a short-lived reporter gene (NlucP). We induced the cells either for $1 \mathrm{~h}$ or continuously with $1000 \mu \mathrm{M}$ benzylideneacetone and found that the reporter reacted with a rapid increase of reporter signal after a $4 \mathrm{~h}$ lag time and showed peak activation after $8 \mathrm{~h}$ (Fig. 1d).

\section{Stable ARE reporter cell lines}

For a first attempt to create a stable ARE cell line we used human keratinocytes (HaCat) as they are of skin origin and were shown to be a good host for ARE reporter constructs [34]. The constructs (Fig. 2a) that were stably integrated contained mulitmerized ARE sequences upstream of a minimal artificial promoter and NlucP as a reporter gene. The constructs further contain a constitutive minimal bidirectional beta actin promoter to drive

A ARE ARE ARE ARE TATA NlucP pA puroR promoter Fluc pA-
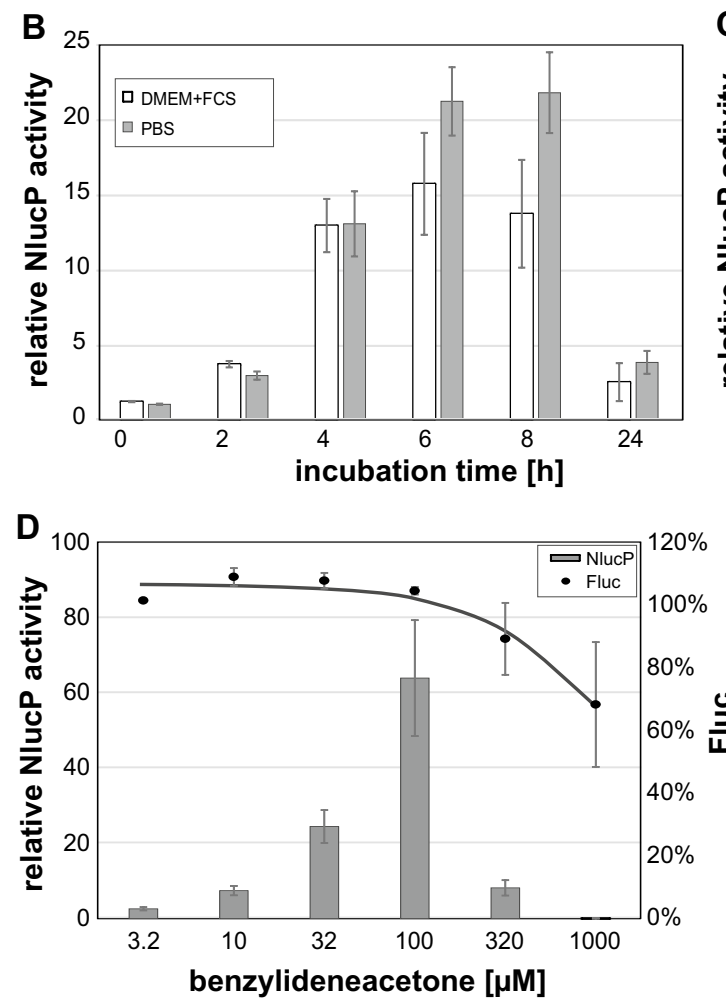

Fig. 2 MDA-ARE reporter cell line. The constructs for the creation of stable cell lines (a) contains multimerized ARE sequences upstream of a minimal promoter (TATA) and NanoLuc with protein and mRNA destabilizing sequences (NlucP) as reporter gene. A bidirectional minimal beta actin promoter is used to drive puromycin resistance gene (puroR) expression and constitutive expression of Fluc as internal reference ( $p A$ polyadenylation signal). For determination of optimal induction conditions cells were treated with $100 \mu \mathrm{M}$ benzylideneacetone in either DMEM including 10\% FCS (DMEM+FCS) or PBS for 0-24 h (b). To demonstrate the function of the internal Fluc reference, cells were treated with increasing concentrations of ethanol
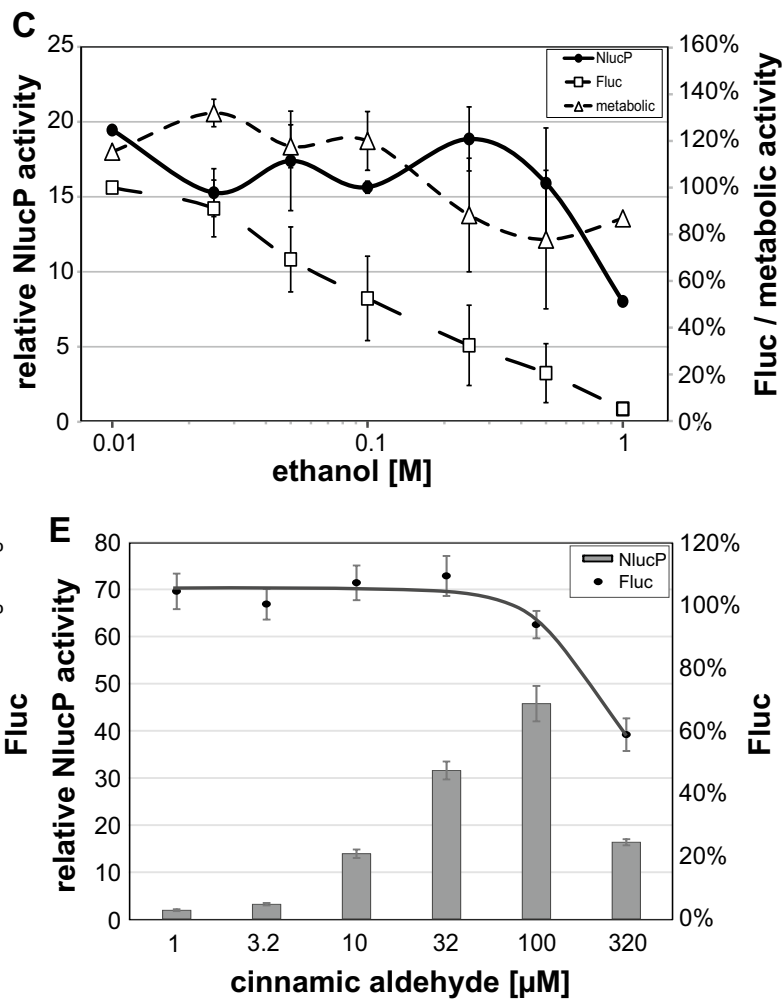

and $32 \mu \mathrm{M}$ benzylidenacetone (c) for $24 \mathrm{~h}$ in PBS or induced with increasing concentrations of benzylideneacetone (d) or cinnamic aldehyde (e) for $6 \mathrm{~h}$ in PBS. For viability measurement a resazurin assay was performed before luciferase measurement (c). Left y-axes show NlucP reporter activity relative to uninduced control cells and right y-axes show relative viability as Fluc relative to uninduced control cells $(\mathbf{c}-\mathbf{e})$ or RFU of generated resorufin relative to uninduced control cells (c; metabolic activity). Curve fit of the Fluc values in (d) and (e) was achieved with the least squares method. All values show means of at least three independent experiments with 12 replicates per plate. Error bars indicate SEM 
the expression of a puromycin resistance gene for selection and Fluc for the use as an internal viability assay (see below). We tested the stable cell lines (either containing AREa or AREb) with different concentrations of benzylideneacetone and sodium dodecyl sulfate (SDS) which was shown to lead to false positive results in the LLNA assay (S1 Fig). Both cell lines (AREa and AREb) showed similar results and were able to detect ARE pathway activation at concentrations of $32 \mu \mathrm{M}$ benzylideneacetone [3.5-fold ( $\pm 0.6 \mathrm{SEM})$ and 2.8-fold ( \pm 0.9 SEM) reporter activation respectively] whereas for SDS both cell lines stayed at background reporter activation. The similar induction levels of the AREa and AREb cell line showed, that the mulitmerized core sequence of $A K R I C 2$ $(\mathrm{AREb})$ is a suitable ARE-Nrf2 reporter.

Although several adaptions were made (ARE sequence, multimerization, reporter gene) the detection limit for sensitizing substances still did not reach the desired low level (32 $\mu \mathrm{M}$ benzylideneacetone). To be able to test extracts with low concentrations of sensitizers, the sensitivity of the reporter assay still demanded adaptations. Wang et al. [42] already stated that higher levels of the transcription factor Nrf2 and Keap1 could lead to a stronger reporter activation. We therefore searched for cell lines with high mRNA expression levels of these two genes in the cBioPortal database [43] and identified the breast cancer cell line MDAMB468 as a potential candidate. We therefore created a stable $4 \times$ AREb NlucP cell line (Fig. 2a) in MDA-MB468 (MDA-AREbn2; referred to as MDA-ARE cell line further on). To lower the detection limit, different induction protocols were tested. Cells were either induced with DMEM $+10 \%$ FCS or in PBS with $100 \mu \mathrm{M}$ benzylideneacetone for 0-24 h (Fig. 2b). The maximum reporter activation was seen for both induction media at 6-8 h. But for the induction level the cells treated in PBS clearly showed higher reporter activation compared to cells treated in DMEM + 10\% FCS [15.7-fold ( \pm 3.4 SEM) maximum activation and 21.7-fold ( \pm 2.7 SEM) maximum activation, respectively]. Although deprived of all nutrients, the cell viability was not obviously disturbed within the first $8 \mathrm{~h}$ (microscopic observation). The tolerance of PBS incubation further leads to the possibility to directly perform extractions in PBS as a polar solvent and add the concentrated extract directly to the cells.

\section{MDA-ARE cell line}

To test the reduced detection limit in the MDA-ARE cell line, benzylideneacetone (Fig. 2d) and cinnamic aldehyde (Fig. 2e) were selected and applied to the cells in PBS at different concentrations for $6 \mathrm{~h}$. Indeed, the lowest concertation for reporter activation was seen at $3.2 \mu \mathrm{M}$ benzylideneacetone (2.6-fold $[ \pm 0.4 \mathrm{SEM}]$ reporter activation, compared to $32 \mu \mathrm{M}$ in the HaCat cell line, (S1 Fig) and $1 \mu \mathrm{M}$ for cinnamic aldehyde (1.8-fold [ \pm 0.2 SEM] reporter activation). Furthermore, even after a short induction time of $2 \mathrm{~h}$, significant reporter activation could be detected [3.3-fold activation $( \pm 0.5$ SEM) for $100 \mu \mathrm{M}$ bezylideneacetone]. An incubation for $24 \mathrm{~h}$ still resulted in high reporter activation however, no improvement over $6 \mathrm{~h}$ incubation concerning the detection limit was observed.

The MDA-ARE cell line also contains a constitutively expressed Fluc. This should provide information about cell viability and cell number. To test this, we detected both luciferases simultaneously with a dual luciferase measurement. The cells were treated with $32 \mu \mathrm{M}$ benzylideneacetone (as a moderately inducing concentration) together with increasing amounts of ethanol as an unspecific toxic insult. Ethanol in this case represents any cytotoxic by-product that might be present in complex extracts of medical devices. In addition to NlucP and Fluc we further used a resazurin assay for determination of cytotoxicity by the means of their metabolic activity (resazurin assay, Fig. 2c). Fluc values started to decrease continuously at concentrations of $0.025 \mathrm{M}$ ethanol indicating a reduced protein synthesis because of cytotoxicity. The resazurin assay on the other hand showed increased signals ( $>100 \%$ compared to cells not treated with EtOH) at low concentrations of ethanol $(0.01-0.1 \mathrm{M})$ indicating an induced metabolic activity of the cells and started decreasing at $0.25 \mathrm{M}$ ethanol. The NlucP reporter showed reduced values starting from $0.5 \mathrm{M}$ ethanol. Fluc values resulted in background levels at $1 \mathrm{M}$ ethanol, whereas the resazurin assay still indicated around $80 \%$ metabolic activity. When tested with pure inducers we observed a drop of Fluc signals at $320 \mu \mathrm{M}$ benzylideneacetone (Fig. 2d) and cinnamic aldehyde (Fig. 2e), which correlates with a drop in NlucP activity at the same concentrations. Therefore, monitoring of the internal reference Fluc provides accurate information about the cell viability on the level of protein homeostasis, in particular when complex mixtures of test substances are applied.

To further characterize the MDA-ARE cell line, we tested the known sensitizers ethylene glycol dimethacrylate (Fig. 3a), cinnamic aldehyde (Fig. 3b), 1,4-benzoquinone (Fig. 3c), and the negative control lactic acid (Fig. 3d) in a broad range of concentrations $(2-2000 \mu \mathrm{M})$ according to the OECD guideline 442D [5]. For viability assessment, we measured the Fluc activity in parallel to the NlucP reporter signal. The MDA-ARE cell line reached maximum inductions (Imax) of 7.5-21.9-fold for the inducers. In all cases, the viability determined via Fluc was greater than $80 \%$ at the level of Imax, indicating that the substances show very specific ARE pathway activation without cytotoxic side effects. The threshold for the categorization of a chemical substance as skin sensitizer was set at 2-fold reporter activation compared to untreated control cells (effective concentration; EC2) and was determined according to the data shown in 
Fig. 3 Validation of the MDAARE reporter cell line. The MDA-ARE reporter cell line was treated with different concentrations of ethylene glycol dimethacrylate (a), cinnamic aldehyde (b), 1,4-benzoquinone (c) or lactic acid (d) for $6 \mathrm{~h}$ in PBS $+1 \%$ DMSO. Left y-axis shows relative NlucP activity relative to cells treated with PBS $+1 \%$ DMSO. Right y-axis (red) shows rel Fluc activity as indicator for cell viability. The blue broken line indicates the EC2 threshold. All values show means of at least three independent experiments with three replicates per plate. Error bars indicate SEM. (Color figure online)
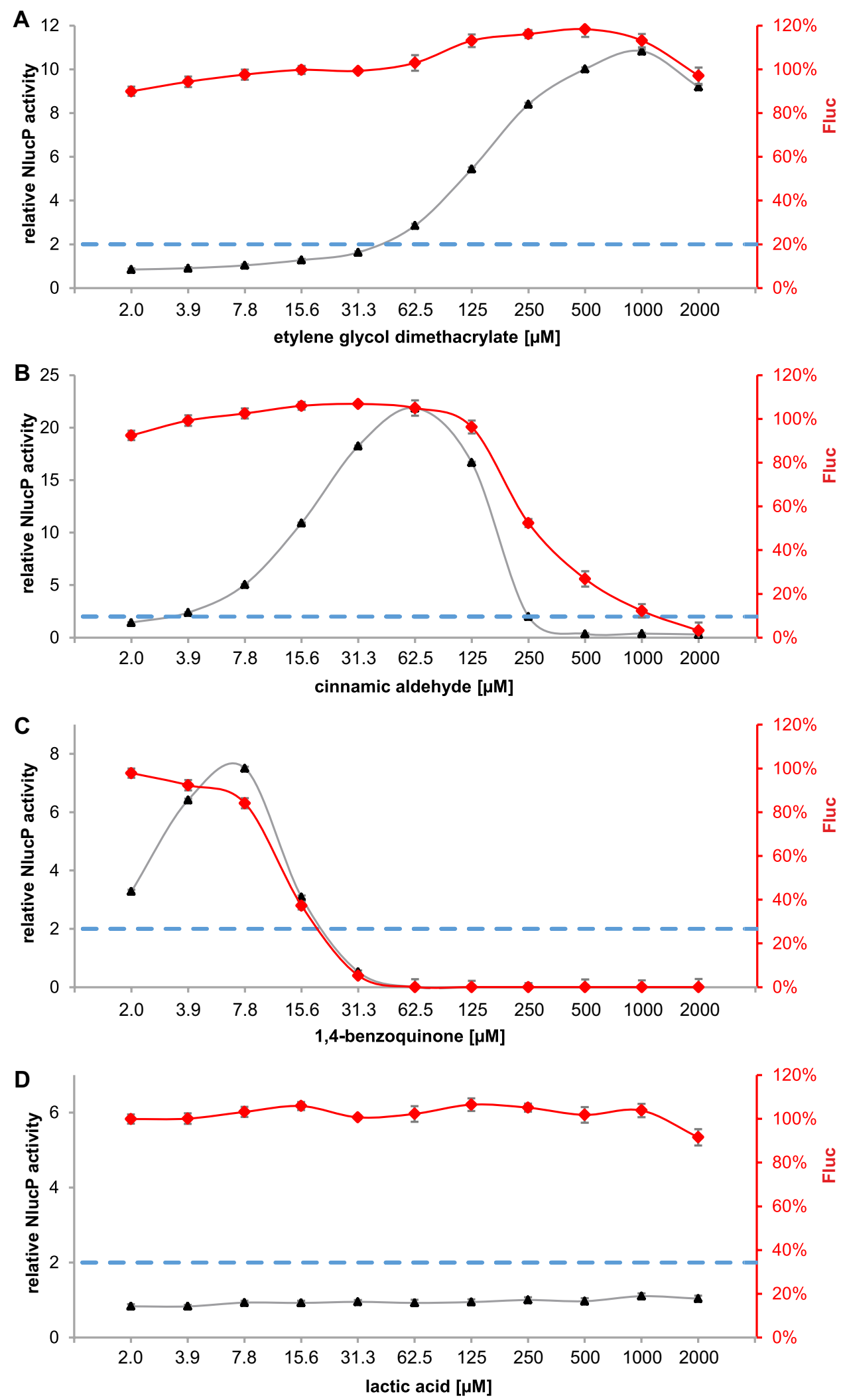

$\longrightarrow$ NlucP activity $\quad-$ threshold $\longrightarrow$ Fluc activity 
Fig. 3 and Table 1. Whereas ethylene glycol dimethacrylate shows no toxicity up to $2000 \mu \mathrm{M}$ (Fig. 3a) the NlucP values and Fluc values of cinnamic aldehyde (Fig. 3b) and 1,4-benzoquinone (Fig. 3c) start to decrease simultaneously after Imax indicating cytotoxic effects. The negative control lactic acid (Fig. 3d) shows neither reporter activation, nor a drop of viability under the tested conditions.

\section{Comparison of the MDA-ARE assay to the LLNA}

The LLNA is still the gold standard when testing medical devices for their ability to cause skin sensitization [49]. To provide an alternative with our newly developed MDA-ARE assay we compared the results obtained from testing pure chemicals according to OECD guideline 442D [5] with data from the LLNA. 22 Different chemicals were screened in triplicate analysis for skin sensitization using the MDAARE assay. A 2-fold induction compared to the negative control was used as threshold above which a sample was classified as sensitizing. Using these criteria 21 out of the 22 substances could be correctly classified as sensitizers or nonsensitizers. Only methyldibromoglutaronitrile, which is a human sensitizer, did not show any induction above 2 in the MDA-ARE assay, although it was detected as a sensitizer in the LLNA (Table 1). In addition, we determined the lowest concentration of tested chemicals that give a positive result in the tests. In the MDA-ARE assay we chose an induction above the MDA-ARE threshold (EC2) and compared it to literature data for the LLNA (EC3). All positively detected chemicals showed an effective concentration considerably lower than the in vivo test (LLNA). Oxazolone was detected at ten times lower concentrations, however, all other tested sensitizers showed positive reactions at concentrations $10^{3}-10^{5}$ times lower than the concentrations that caused a positive result in the LLNA (Table 1). SDS which is known to show a false positive response in the LLNA, was classified correctly as a non-sensitizing substance in the MDA-ARE assay, as did the non-sensitizing substances salicylic acid, glycerol and lactic acid.
Table 1 Comparison of the lowest concentrations of pure chemicals causing a positive test result in the MDA-ARE assay and the LLNA

\begin{tabular}{|c|c|c|c|c|}
\hline & \multirow[t]{2}{*}{ CAS no. } & \multicolumn{2}{|l|}{ LLNA } & \multirow{2}{*}{$\begin{array}{l}\text { MDA-ARE } \\
\mathrm{EC} 2[\mu \mathrm{M}]\end{array}$} \\
\hline & & $\mathrm{EC} 3[\mu \mathrm{M}]$ & Literature & \\
\hline \multicolumn{5}{|l|}{ Sensitizers } \\
\hline Oxazolone & $15646-46-5$ & 460 & [44] & 36.2 \\
\hline 1,4-Benzoquinone & $106-51-4$ & 916 & [45] & 0.6 \\
\hline 2,4-Dinitrochlorobenzene & $97-00-7$ & 2469 & [45] & 1.4 \\
\hline 4-Nitrobenzylbromide & $100-11-8$ & 2314 & [17] & 1.4 \\
\hline Glyoxal & $107-22-2$ & 241,213 & [17] & 27.7 \\
\hline Methyldibromoglutaronitrile & $35691-65-7$ & 48,883 & [46] & n.i. \\
\hline Cinnamic aldehyde & $104-55-2$ & 226,998 & [45] & 2.0 \\
\hline Isoeugenol & $97-54-1$ & 91,352 & [46] & 33.8 \\
\hline Ethylene glycol dimethacrylate & $97-90-5$ & $1,765,715$ & [44] & 59.1 \\
\hline 2-Mercaptobenzothiazole & $149-30-4$ & 580,005 & {$[44]$} & 16.4 \\
\hline Tetramethyl thiuram disulphide & $137-26-8$ & 216,279 & [45] & 5.8 \\
\hline Eugenol & $97-53-0$ & 791,717 & [45] & 345 \\
\hline Cinnamic alcohol & $104-54-1$ & $1,565,179$ & {$[45]$} & 74.5 \\
\hline \multicolumn{5}{|l|}{ Non-sensitizers } \\
\hline Sodium dodecyl sulfate & $151-21-3$ & 485,484 & {$[45]$} & n.i. \\
\hline Salicylic acid & $69-72-7$ & - & {$[45]$} & n.i. \\
\hline Glycerol & $56-81-5$ & - & [45] & n.i. \\
\hline Lactic acid & $50-21-5$ & - & [45] & n.i. \\
\hline Methyl salicylate & $119-36-8$ & - & [45] & n.i. \\
\hline Diethylphthalate & $84-66-2$ & - & {$[45]$} & n.i. \\
\hline Sulfanilamide & $63-74-1$ & - & [45] & n.i. \\
\hline Chlorobenzene & $108-90-7$ & - & {$[45]$} & n.i. \\
\hline Isopropanol & $67-63-0$ & - & [45] & n.i. \\
\hline
\end{tabular}

22 Pure chemicals (qualified as sensitizers and non-sensitizers for humans according to [5, 47, 48]) were tested with the MDA-ARE ARE reporter cell line. The lowest concentration showing a fold induction above 2 was recorded (EC2) and compared to the lowest concentration showing a stimulation index of 3 in the LLNA (EC3). n. $i$ no induction $>2$ 


\section{MDA-ARE assay for testing extracts}

To test if the MDA-ARE assay is suitable for detection of skin sensitizers in extracts of medical devices, we prepared silicone samples spiked with $0.1 \%$ cinnamic aldehyde, 1,4-benzoquinone or 2,4-dinitrochlorobenzene. We then performed extractions of these samples (silicone $+0.1 \%$ incorporated sensitizers) according to ISO 10993-12:2012 [32] with a polar (PBS) and a non-polar (DMSO) solvent. Results of the extracts of the spiked silicone samples and pure silicone samples (blank) as negative controls are shown in Fig. 4. For measurement, extracts were diluted in PBS from 1 to $0.031 \%$. The viability (determined by Fluc measurement) and the reporter induction (determined by NlucP activity) of the sample extracts were recorded. To check if components of the extracts have a negative influence on the ARE reporter activation we used a parallel approach where $32 \mu \mathrm{M}$ cinnamic aldehyde was added to all dilutions of the extracts as positive control. For all three tested skin sensitizers an elevation of the induction above 2-fold could be detected in at least one of the two extracts (PBS or DMSO). For extracts of silicone spiked with $0.1 \%$ cinnamic aldehyde an induction above 2 was observed for $1 \%$ PBS, resulting in a lowest ineffective dilution (LID) of 0.005 (Fig. 4a). The LID value refers to the lowest dilution of the sample which showed a negative result in the assay. The corresponding DMSO extract showed higher activities (LID 0.00125 ). The extracts of silicone spiked with $0.1 \%$ 1,4-benzoquinone showed activation of the NlucP signal from 1 to $0.25 \%$ in PBS (LID 0.005 and 0.00125 , respectively), but not in DMSO (Fig. 4b). Silicone samples spiked with $0.1 \%$ 2,4-dinitrochlorobenzene activated the NlucP reporter for both PBS (LID 0.0025) and DMSO extracts (LID 0.00125). At higher concentrations of the DMSO extract (0.5-1\% extract in the sample), cytotoxic effects of the samples were observed (Fig. 4c), which did not appear in any of the PBS extracts. Furthermore, PBS extracts did not affect the induction of the positive control, whereas DMSO extracts at high concentrations reduced these values (Figs. 4a', b' and c'). Extracts of the pure silicone did not show any significant change of either the Fluc or NlucP activity (Figs. 4d and d'). After the proof of concept with the silicone extracts, we tested polar and non-polar extracts of medical devices (Table 2). In 40 samples tested, 12 (30\%) showed a fold induction higher than two in either the polar extract $(n=3)$ or the non-polar extract $(n=9)$. Materials that were classified as potentially skin sensitizing include acrylic resins, silicone, fluoroelastomers (FKM), silicone rubber-vinyl methyl silicone (VMQ), latex, thermoplastic polymers (TPE), metals and rubber. One sample was cytotoxic in the polar extracts (viability below 70\%) and five samples were cytotoxic in the non-polar extracts. In three of these samples, adding cinnamic aldehyde $(32 \mu \mathrm{M})$ to the extracts as a positive control did not lead to a fold induction above 2 because of the cytotoxic effects.

\section{Discussion}

Recently, different in vitro assays for the detection of skin sensitization have been developed. In this context, OECD guidelines have been published and ECVAM validation of some methods has taken place. Still, most of these methods focus on the detection of pure chemicals and so far for state of the art testing of medical devices in vivo tests have to be used.

A major step towards in vitro testing was driven by the EU Cosmetic Directives 76/768/EEC, banning animal tests for assessment of cosmetics [20]. The first cell-based assay published by the OECD was the KeratinoSens assay followed by the LuSens [5]. Although not published by the OECD, other cell-based assays based on the ARE-Nrf2 pathway have been developed [12, 42]. These cell lines were selected for high induction levels and their ability to correctly discriminate between sensitizers and non-sensitizers [34, 35, 42]. In case of extracts of medical devices, the requirements are quite different and existing in vitro methods are not suitable so far. Non-polar solvents, as required for medical device extraction are either not soluble in cell culture medium (plant oils) or show cytotoxic effects on the cells even in low concentrations [32]. Through evaporation, the solvent can be replaced by a polar, non-toxic solvent, but within this step, crucial substances can get lost [50, 51]. To avoid losses during solvent exchange, DMSO was chosen in our approach as extraction solvent. DMSO is less toxic to cells than other organic solvents, and can be used in cell culture medium up to a final concentration of $1 \%$. Nevertheless, a dilution step of the extracts by a factor of 100 is required. Therefore, the aim was to reduce the detection limit of sensitizers in complex solutions. The AREb sequence (ARE core sequence of $A K R 1 C 2$ ) demonstrated that the core binding site for Nrf2 is sufficient for a robust reporter activation after induction, whereas minor contributions are mediated by the flanking sequences of AREa. The complete loss of reporter activation upon mutation of the AP-1 binding site within the ARE core sequence of $A K R 1 C 2$ was unexpected, as it does not interfere with the Nrf2 consensus binding site [40]. Nevertheless, the role of members of the Jun protein family was already demonstrated for other antioxidant response promoters [52-54]. Although the AREd sequence of mouse Gstal has worked well in a liver cell line [35] it did not show induction in HEK293. This effect of different induction potential of ARE reports in different cell lines was also already observed for another reporter construct, which worked well in an MCF-7 context [42] but failed to give robust induction in HaCat cells [34]. Although MDA-MB468 cells are not involved in 

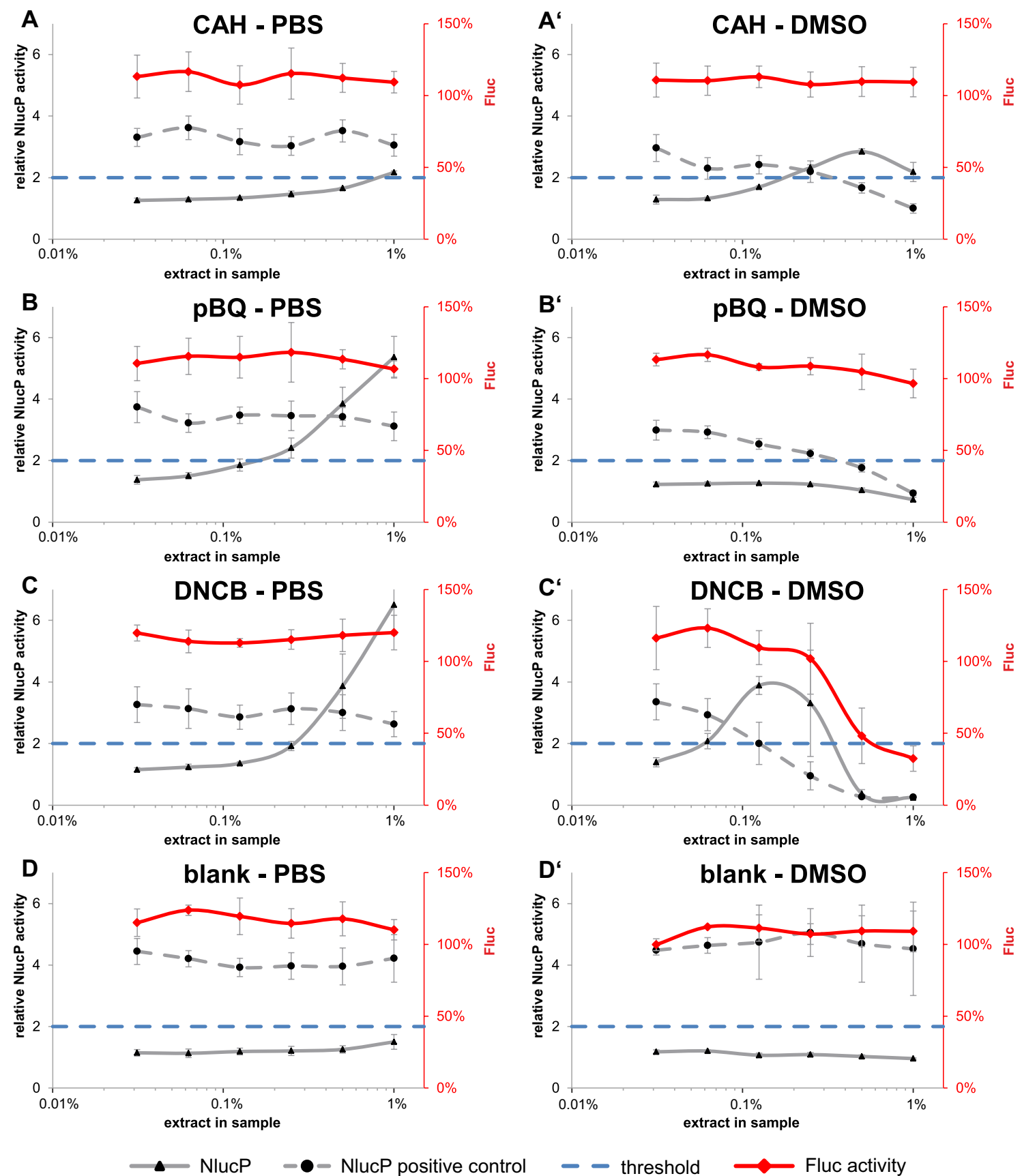

Fig. 4 Results for spiked medical silicone. Silicone with incorporated sensitizing substances $(0.1 \% \mathrm{w} / \mathrm{w})$ were extracted. Extract concentrations $(0.031-1 \%)$ in PBS of these silicone samples of the indicated chemicals, cinnamic aldehyde (CAH) (a and a'), 1,4-benzoquinone (pBQ) (b and b'), 2,4-dinitrochlorobenzene (DNCB) (c and $\left.\mathbf{c}^{\prime}\right)$, or without addition (blank) (d and d') were tested with the MDA-ARE assay. The left $y$-axis shows the fold induction of the samples (NlucP)

the process of skin sensitization in vivo, they still represent a very sensitive model for the ARE-Nrf2 pathway. We chose the cell line because of its high levels of Nrf2 as well as Keap1. An overexpression of Nrf2 alone in our hands only resulted in increased background luciferase levels. However,

or the positive control (NlucP positive control, sample extract with $32 \mu \mathrm{M}$ cinnamic aldehyde added) relative to control cells (treated with PBS $+1 \%$ DMSO). The right y-axis shows viability of the cells relative to control cells (Fluc). The blue broken line indicates the EC2 threshold. All values are mean values from at least six wells treated with at least two independent extracts. Error bars indicate SD. (Color figure online)

there are reports showing an increased level of Nrf2 leads to an increased background as well as increased pathway activation [42, 55], but this might again be cell line specific and dependent on endogenous Keap1 levels. In our hands, the MDA-ARE cell line reached a $\sim$-fold higher induction 
Table 2 Testing of real sample extracts of medical devices

\begin{tabular}{|c|c|c|c|c|c|c|c|c|}
\hline \multirow[t]{2}{*}{ Type of device } & \multirow[t]{2}{*}{ Material } & \multicolumn{3}{|l|}{ Polar extract } & \multicolumn{3}{|l|}{ Non-polar extract } & \multirow{2}{*}{$\begin{array}{l}\text { Classification } \\
\text { Sensitizing } \\
\text { potential }\end{array}$} \\
\hline & & Viability $[\%] \pm S D$ & Fold induction & Pos ctrl & Viability $[\%] \pm S D$ & Fold induction & Pos ctrl & \\
\hline Hearing device & Acrylic resin & $92 \pm 12$ & $2.88 \pm 0.55$ & Yes & $67 \pm 10$ & $0.52 \pm 0.05$ & No & Yes \\
\hline Hearing device & Silicone + coating & $103 \pm 2$ & $3.95 \pm 0$ & Yes & $116 \pm 10$ & $1.39 \pm 0.07$ & Yes & Yes \\
\hline Dentistry device & FKM, VMQ, & $99 \pm 9$ & $1.09 \pm 0.07$ & Yes & $51 \pm 2$ & $3.3 \pm 0.39$ & Yes & Yes \\
\hline Antimicrob. spray & Liquid & $82 \pm 13$ & $1.08 \pm 0.13$ & Yes & $52 \pm 7$ & $1.34 \pm 0.4$ & Yes & No \\
\hline Implant-prototype & Epoxy resin & $115 \pm 13$ & $1.25 \pm 0.19$ & Yes & $121 \pm 10$ & $0.87 \pm 0.15$ & Yes & No \\
\hline Implant & Silicone & $117 \pm 12$ & $1.22 \pm 0.1$ & Yes & $102 \pm 14$ & $2.98 \pm 0.33$ & Yes & Yes \\
\hline Implant & Silicone & $119 \pm 13$ & $1.26 \pm 0.12$ & Yes & $93 \pm 5$ & $1.39 \pm 0.17$ & Yes & No \\
\hline Needle & Stainless steel & $88 \pm 16$ & $1.24 \pm 0.26$ & Yes & $104 \pm 13$ & $1.17 \pm 0.11$ & Yes & No \\
\hline Implant-prototype & Epoxy resin & $91 \pm 2$ & $0.68 \pm 0.08$ & Yes & $126 \pm 18$ & $1.27 \pm 0.08$ & Yes & No \\
\hline Implant-prototype & Epoxy resin & $78 \pm 7$ & $0.84 \pm 0.1$ & Yes & $129 \pm 4$ & $1.15 \pm 0.03$ & Yes & No \\
\hline Implant-prototype & Epoxy resin & $94 \pm 6$ & $0.99 \pm 0.12$ & Yes & $82 \pm 9$ & $0.95 \pm 0.14$ & Yes & No \\
\hline Infrared device & Plastics & $100 \pm 6$ & $1.24 \pm 0.1$ & Yes & $76 \pm 7$ & $1.06 \pm 0.04$ & Yes & No \\
\hline Implant-prototype & Carbone fibre & $122 \pm 6$ & $1.39 \pm 0.15$ & Yes & $83 \pm 19$ & $0.81 \pm 0.12$ & Yes & No \\
\hline Implant & $\mathrm{PE}$ and $\mathrm{PP}$ & $100 \pm 15$ & $1.01 \pm 0.09$ & Yes & $102 \pm 10$ & $1.26 \pm 0.16$ & Yes & No \\
\hline Gloves & Nitrile, purple & $93 \pm 10$ & $1.19 \pm 0.01$ & Yes & $31 \pm 8$ & $0.79 \pm 0.04$ & No & $\mathrm{Ncc}$ \\
\hline Gloves & Nitrile, blue & $108 \pm 14$ & $1.66 \pm 0.13$ & Yes & $5 \pm 6$ & $0.67 \pm 0.01$ & No & $\mathrm{Ncc}$ \\
\hline Gloves & Latex, white & $91 \pm 10$ & $1.35 \pm 0.28$ & Yes & $113 \pm 7$ & $2.78 \pm 0.2$ & Yes & Yes \\
\hline Gloves & Latex, green & $75 \pm 2$ & $3.54 \pm 0.3$ & Yes & $84 \pm 17$ & $1.38 \pm 0.4$ & Yes & Yes \\
\hline Laboratory device & Thermoplast & $102 \pm 7$ & $1.28 \pm 0.3$ & Yes & $99 \pm 8$ & $1.69 \pm 0.13$ & Yes & No \\
\hline Hearing device & DLPA acrylate & $114 \pm 12$ & $1.25 \pm 0.11$ & Yes & $95 \pm 11$ & $3.06 \pm 0.57$ & Yes & Yes \\
\hline Hearing device & DLPA acrylate & $86 \pm 7$ & $1.65 \pm 0.14$ & Yes & $129 \pm 9$ & $2.31 \pm 0.18$ & Yes & Yes \\
\hline Hearing device & TPU & $91 \pm 16$ & $1.05 \pm 0.31$ & Yes & $83 \pm 17$ & $0.87 \pm 0.12$ & Yes & No \\
\hline Prothesis & Coating & $80 \pm 14$ & $0.97 \pm 0.17$ & Yes & $91 \pm 3$ & $1.03 \pm 0.1$ & Yes & No \\
\hline Prothesis & TPE, PC & $114 \pm 14$ & $1.1 \pm 0.06$ & Yes & $109 \pm 6$ & $3.85 \pm 0.31$ & Yes & Yes \\
\hline Suture & Silicone & $110 \pm 7$ & $0.89 \pm 0.11$ & Yes & $112 \pm 13$ & $1.17 \pm 0.25$ & Yes & No \\
\hline Suture & Silicone & $81 \pm 12$ & $1.04 \pm 0.13$ & Yes & $88 \pm 13$ & $0.81 \pm 0.09$ & Yes & No \\
\hline Suture & PES & $90 \pm 11$ & $0.66 \pm 0.34$ & Yes & $124 \pm 14$ & $1.12 \pm 0.17$ & Yes & No \\
\hline Active coal & Coal & $62 \pm 8$ & $0.67 \pm 0.14$ & Yes & $92 \pm 8$ & $0.68 \pm 0.19$ & Yes & No \\
\hline Active coal & Coal & $82 \pm 9$ & $0.77 \pm 0.13$ & Yes & $92 \pm 12$ & $0.76 \pm 0.15$ & Yes & No \\
\hline Dentistry device & Glass and metals & $81 \pm 9$ & $1.17 \pm 0.02$ & Yes & $73 \pm 5$ & $2.76 \pm 0.12$ & Yes & Yes \\
\hline Hearing device & Silicone, parts & $78 \pm 3$ & $0.76 \pm 0.06$ & Yes & $78 \pm 5$ & $0.6 \pm 0.06$ & Yes & No \\
\hline Hearing device & ABS & $89 \pm 3$ & $0.8 \pm 0.05$ & Yes & $87 \pm 6$ & $0.96 \pm 0.41$ & Yes & No \\
\hline Hearing device & Rubber & $95 \pm 4$ & $0.84 \pm 0.08$ & Yes & $98 \pm 10$ & $2.03 \pm 0.08$ & Yes & Yes \\
\hline Hearing device & TPE-A & $107 \pm 6$ & $0.89 \pm 0.1$ & Yes & $90 \pm 5$ & $0.94 \pm 0.08$ & Yes & No \\
\hline Hearing device & TPE-A, brown & $103 \pm 7$ & $1.73 \pm 0.07$ & Yes & $91 \pm 10$ & $1.02 \pm 0.12$ & Yes & No \\
\hline Hearing device & Silicone, parts & $88 \pm 12$ & $0.7 \pm 0.11$ & Yes & $92 \pm 10$ & $0.92 \pm 0.13$ & Yes & No \\
\hline Hearing device & TPE-A & $101 \pm 9$ & $1.04 \pm 0.03$ & Yes & $109 \pm 10$ & $1.09 \pm 0.11$ & Yes & No \\
\hline Menstrual cup & Latex & $89 \pm 10$ & $0.88 \pm 0.24$ & Yes & $71 \pm 12$ & $2.46 \pm 0.23$ & Yes & Yes \\
\hline Menstrual cup & TPE & $102 \pm 6$ & $1.01 \pm 0.14$ & Yes & $98 \pm 12$ & $1.29 \pm 0.13$ & Yes & No \\
\hline Menstrual cup & Silicone & $82 \pm 8$ & $1.07 \pm 0.04$ & Yes & $111 \pm 12$ & $1.09 \pm 0.2$ & Yes & No \\
\hline
\end{tabular}

40 Medical devices were extracted with a polar (PBS) and a non-polar (DMSO) solvent and tested with the MDA-ARE assay. The table shows viability of each sample extract and its fold induction. Reduced viability is indicated by italics; fold induction above the threshold 2 is highlighted in bold. Furthermore, $32 \mu \mathrm{M}$ cinnamic aldehyde was added to the extracts as positive control (pos ctrl) and measured with the MDAARE assay. If the fold induction of the positive control was above the threshold 2 "yes" is indicated in the table. Classification of the sensitizing potential is shown as "yes" if the fold induction of at least one of the two extracts is above the threshold of 2. \pm Values represent SD. Classification is shown as "no" if the fold induction of both extracts is lower than two and the pos ctrl is higher than two (yes). For cytotoxic samples where the pos ctrl of at least one of the two samples was lower than the threshold of 2 no clear classification (ncc) was possible

compared to the HaCat cell line under the same induction conditions (compare Fig. 2b-S1 Fig A).

ARE pathway activation is mediated by the interaction of small reactive molecules (like haptens) with proteins.
The optimal growth medium for cultured cells contains a large number of proteins due to the supplemented serum. Therefore, the reactive molecules could bind to serum proteins before entering the cells and interacting with Keap1. 
A serum reduction as done for other ARE cell lines [34] can therefore improve the pathway response. As we created a reporter cell line with a maximum induction after 6-8 h, we could reduce the time of compound incubation and therefore could completely deplete the medium of serum without a major impact on cell viability and proliferation. We decided to use PBS alone as general induction medium, because this provides the opportunity to use pure extracts of medical devices if they were performed in PBS, which further increases the sensitivity of the assay by a factor of 100. Another advantage when using shorter incubation time is that possible cytotoxic effects can be reduced compared to longer incubation times.

When testing substances and mixtures for their ability to induce the ARE-Nrf2 pathway, the cytotoxicity is always critical and was found to be the main limiting factor for the assessment of more complex formulations and plant extracts with the KeratinoSens assay [56, 57]. Substances were shown to give false positive results when cells suffer severe toxic effects [34] and complex formulations can give false negative results if cytotoxicity is reached before the pathway is activated [57]. The latter problem is solved in the MDA-ARE assay by reducing the incubation time to $6 \mathrm{~h}$ where often critical cytotoxic effects are not reached. For the problem of false positive effects, a parallel viability assay based on the metabolic activity of the cells (MTT or resazurin based assays) is already in use in other assays [34, 58]. Results gained from the luciferase measurement of an ARE reporter is considered to be significant, when the cell viability is greater than $70 \%$. For our assay we compared a resazurin assay with a Fluc based internal reference. We found that especially the Fluc activity sensitively reacted to cytotoxic effects (Figs. 3b-c) and correlates well with the drop in NlucP reporter signal due to cytotoxicity. The Fluc measurement can be used as an alternative for metabolic based viability assays and prevents overestimation of cell viability that may be caused by metabolic hyperactivation induced by extract compounds.

One major goal of the project was that the developed assay should be able to detect skin sensitizers in complex mixtures at the same concentration levels or lower as the in vivo assay LLNA, which is currently used for the testing of medical devices for skin sensitization. We therefore performed full dose response curves with wellknown sensitizers as well as non-sensitizers. In total, 21 out of 22 pure chemicals were correctly identified as sensitizers or non-sensitizers by the MDA-ARE assay. This results in $92 \%$ toxicological sensitivity and $100 \%$ specificity although, more pure substances need to be tested in the future to refine and secure these results. In extracts, low concentrations of sensitizers limit their detection. Except for two substances (oxazolone and methyldibromoglutaronitrile) all other chemicals were detected in the
MDA-ARE assay at concentration more than 1000-fold lower than with the LLNA. Therefore even a dilution step of 100 (for non-polar extracts in our procedure) still results in lower detection limits for the MDA-ARE assay compared to the LLNA.

To assess skin sensitization of medical devices, McKim and colleagues tested different vehicles spiked with sensitizers and showed responses of skin models (Epiderm and SkinEthik) towards the applied testing matrix [29]. Furthermore, Coleman and colleagues integrated skin sensitizers in silicone samples and could demonstrate a reaction of skin models (SenCeeTox) towards the extracts [15]. By assessing various endpoints they could detect skin sensitizers in silicone samples at a concentration of $10 \% \mathrm{w} / \mathrm{w}$. However, a concentration of $10 \% \mathrm{w} / \mathrm{w}$ of a strong skin sensitizer seems unlikely in a medical device. Therefore, we prepared comparable silicon samples with $0.1 \% \mathrm{w} / \mathrm{w}$ and could easily detect the sensitizers by using an ARE-Nrf2 reporter gene assay. The assay allows application of both polar and nonpolar solvents, which turned out to be critical depending on the solubility properties of the chemicals (Fig. 4; [59]).

The testing of extracts of medical devices showed that the MDA-ARE assay is sensitive enough to detect sensitizing agents in real world samples. The parallel assessment of the cell viability and the use of positive controls are essential to evaluate the results of the reporter assay because of the great variability in extract composition of the different materials. The strategy of using polar as well as non-polar extraction methods as in ISO 10993-12:2012 [32] is of great importance because several samples in our assay only tested positive in one of the extracts. Different reactivity in polar (saline) and non-polar (sesame oil) extracts was also described for the SenCeeTox assay [15].

Summarizing, the MDA-ARE assay is a suitable screening tool for detection of skin sensitizers in medical device extracts especially during product development. Both polar and non-polar extracts can be applied, it provides high sensitivity and low detection limits and its internal reference allows sensitive viability assessments. Furthermore, the assay time of only $6 \mathrm{~h}$ from induction to measurement delivers results of tested extracts within 1 single day. As a next step, we will compare the results of the medical devices from the MDA-ARE assay to the DPRA assay and animal tests.

As a conclusion, the MDA-ARE assay could be a useful tool for assessment of skin sensitizing potential of medical device extracts within an ITS combining various assays addressing the key events of the AOP for skin sensitization.

Acknowledgements Open access funding provided by FH Campus Wien - University of Applied Sciences. The work was supported by the Austrian Research Promotion Agency (FFG, Grant 839053) and the City of Vienna (MA23-project 18-18). 
Author contributions EM, ER, NG, GE, GL, SA, MH, AW and CS were responsible for experimental design, analysis, execution and writing of the manuscript. $\mathrm{CK}$ and $\mathrm{TC}$ were responsible for experimental design, analysis, writing, communication, and supervision of the project. All authors read and approved the final manuscript.

\section{Compliance with ethical standards}

Conflict of interest The authors declare no conflict of interest.

Open Access This article is distributed under the terms of the Creative Commons Attribution 4.0 International License (http://creativeco mmons.org/licenses/by/4.0/), which permits unrestricted use, distribution, and reproduction in any medium, provided you give appropriate credit to the original author(s) and the source, provide a link to the Creative Commons license, and indicate if changes were made.

\section{References}

1. ISO (2009) ISO 10993-1:2009- Biological evaluation of medical devices - part 1: evaluation and testing within a risk management process. https://www.iso.org/standard/44908.html

2. ISO (2010) ISO 10993-10:2010- Biological evaluation of medical devices-part 10: tests for irritation and skin sensitization. https ://www.iso.org/standard/40884.html

3. Basketter D, Jírova D, Kandárová H (2012) Review of skin irritation/corrosion hazards on the basis of human data: a regulatory perspective. Interdiscip Toxicol 5:98-104. https://doi.org/10.2478/ v10102-012-0017-2

4. OECD (2015) Test No. 442C: In vitro Skin Sensitisation: Direct Peptide Reactivity Assay (DPRA). https://doi.org/10.1787/97892 64264359-en

5. OECD (2018) Test No. 442D: In vitro Skin Sensitisation, ARENrf2 Luciferase Test Method. https://doi.org/10.1787/9789264229 822-en

6. OECD (2016) Test No. 442E: In vitro Skin Sensitisation. Human Cell Line Activation Test (h-CLAT). OECD Guidel Test Chem Draft Propos. https://doi.org/10.1787/9789264264359-en

7. MacKay C (2013) From pathways to people: applying the adverse outcome pathway (AOP) for skin sensitization to risk assessment. Altex 30:473-486. https://doi.org/10.14573/altex.2013.4.473

8. OECD (1992) Test No. 406: Skin Sensitisation. 406:9. https://doi. org/10.1787/9789264070660-en

9. Buehler EV (1965) Delayed contact hypersensitivity in the guinea pig. Arch Dermatol 91:171-177

10. Magnusson B, Kligman AM (1970) Allergic contact dermatitis in the guinea pig. Charles C. Thomas, Springfield

11. Russell WMS, Burch RL, Hume CW (1959) The principles of humane experimental techniques. Charles C. Thomas, Springfield

12. Bauch C, Kolle SN, Ramirez T et al (2012) Putting the parts together: combining in vitro methods to test for skin sensitizing potentials. Regul Toxicol Pharmacol 63:489-504. https://doi. org/10.1016/j.yrtph.2012.05.013

13. Gordon S (2015) Non-animal models of epithelial barriers (skin, intestine and lung) in research, industrial applications and regulatory toxicology. Altex 32:327-378. https://doi.org/10.14573/altex .1510051

14. Peiser M, Tralau T, Heidler J et al (2011) Allergic contact dermatitis: epidemiology, molecular mechanisms, in vitro methods and regulatory aspects. Current knowledge assembled at an international workshop at BfR, Germany. Cell Mol Life Sci 69:763-781. https://doi.org/10.1007/s00018-011-0846-8
15. Coleman KP, McNamara LR, Grailer TP et al (2015) Evaluation of an in vitro human dermal sensitization test for use with medical device extracts. Appl Vitr Toxicol 1:118-130. https:// doi.org/10.1089/aivt.2015.0007

16. Timm M, Saaby L, Moesby L, Hansen EW (2013) Considerations regarding use of solvents in in vitro cell based assays. Cytotechnology 65:887-894. https://doi.org/10.1007/s 1061 6-012-9530-6

17. Natsch A, Ryan CA, Foertsch L et al (2013) A dataset on 145 chemicals tested in alternative assays for skin sensitization undergoing prevalidation. J Appl Toxicol 33:1337-1352. https ://doi.org/10.1002/jat.2868

18. Jowsey IR, Basketter DA, Westmoreland C, Kimber I (2006) A future approach to measuring relative skin sensitising potency: a proposal. J Appl Toxicol 26:341-350. https://doi.org/10.1002/ jat. 1146

19. Rovida C (2008) Integrated testing strategies (ITS) for safety assessment. Altex 32:25-40. https://doi.org/10.14573/altex .1411011

20. European Commission (2003) Directive 2003/15/EC of the European Parliament and of the Council of 27 February 2003 amending Council Directive 76/768/EEC on the approximation of the laws of the Member States relating to cosmetic products. Off J L 66

21. Strickland J, Zang Q, Kleinstreuer N et al (2016) Integrated decision strategies for skin sensitization hazard. J Appl Toxicol 36:1150-1162. https://doi.org/10.1002/jat.3281

22. Canipa SJ, Chilton ML, Hemingway R et al (2017) A quantitative in silico model for predicting skin sensitization using a nearest neighbours approach within expert-derived structureactivity alert spaces. J Appl Toxicol 37:985-995. https://doi. org/10.1002/jat.3448

23. Verheyen GR, Braeken E, Van Deun K, Van Miert S (2017) Evaluation of in silico tools to predict the skin sensitization potential of chemicals. SAR QSAR Environ Res 28:59-73. https ://doi.org/10.1080/1062936X.2017.1278617

24. Goebel C, Aeby P, Ade N et al (2012) Guiding principles for the implementation of non-animal safety assessment approaches for cosmetics: skin sensitisation. Regul Toxicol Pharmacol 63:40 52. https://doi.org/10.1016/j.yrtph.2012.02.007

25. Dearden JC, Hewitt M, Roberts DW et al (2015) Mechanismbased QSAR modeling of skin sensitization. Chem Res Toxicol 28:1975-1986. https://doi.org/10.1021/acs.chemrestox.5b00197 Epub 2015 Oct 5

26. Aznar M, Rodriguez-Lafuente A, Alfaro P, Nerin C (2012) UPLC-Q-TOF-MS analysis of non-volatile migrants from new active packaging materials. Anal Bioanal Chem 404:19451957. https://doi.org/10.1007/s00216-012-6247-5

27. Nerin C, Alfaro P, Aznar M, Domeño C (2013) The challenge of identifying non-intentionally added substances from food packaging materials: a review. Anal Chim Acta 775:14-24. https:// doi.org/10.1016/j.aca.2013.02.028

28. Natsch A, Emter R (2008) Skin sensitizers induce antioxidant response element dependent genes: application to the in vitro testing of the sensitization potential of chemicals. Toxicol Sci 102:110-119. https://doi.org/10.1093/toxsci/kfm259

29. McKim JM, Keller DJ, Gorski JR (2012) An in vitro method for detecting chemical sensitization using human reconstructed skin models and its applicability to cosmetic, pharmaceutical, and medical device safety testing. Cutan Ocul Toxicol 31:292-305. https://doi.org/10.3109/15569527.2012.667031

30. Kensler TW, Wakabayashi N, Biswal S (2007) Cell survival responses to environmental stresses via the Keap1-Nrf2-ARE pathway. Annu Rev Pharmacol Toxicol 47:89-116. https://doi. org/10.1146/annurev.pharmtox.46.120604.141046 
31. Casati S, Aeby P, Kimber I et al (2009) Selection of chemicals for the development and evaluation of in vitro methods for skin sensitisation testing. Altern Lab Anim 37:305-312

32. ISO (2012) ISO 10993-12:2012. Biological evaluation of medical devices—sample preparation and reference materials. https:// www.iso.org/standard/53468.html

33. Riegel E, Heimbucher T, Höfer T, Czerny T (2017) A sensitive, semi-quantitative mammalian two-hybrid assay. Biotechniques 62:206-214. https://doi.org/10.2144/000114544

34. Emter R, Ellis G, Natsch A (2010) Performance of a novel keratinocyte-based reporter cell line to screen skin sensitizers in vitro. Toxicol Appl Pharmacol 245:281-290. https://doi. org/10.1016/j.taap.2010.03.009

35. Boerboom A-MJF, Vermeulen M, van der Woude H et al (2006) Newly constructed stable reporter cell lines for mechanistic studies on electrophile-responsive element-mediated gene expression reveal a role for flavonoid planarity. Biochem Pharmacol 72:217 226. https://doi.org/10.1016/j.bcp.2006.04.002

36. Hall MP, Unch J, Binkowski BF et al (2012) engineered luciferase reporter from a deep sea shrimp utilizing a novel imidazopyrazinone substrate. ACS Chem Biol 7:1848-1857. https://doi. org/10.1021/cb3002478

37. Voon DC, Subrata LS, Baltic S et al (2005) Use of mRNA- and protein-destabilizing elements to develop a highly responsive reporter system. Nucleic Acids Res 33:e27-e27. https://doi. org/10.1093/nar/gni030

38. Wilson MH, Coates CJ, George AL (2007) PiggyBac transposonmediated gene transfer in human cells. Mol Ther 15:139-145. https://doi.org/10.1038/sj.mt.6300028

39. Vancha AR, Govindaraju S, Parsa KVL et al (2004) Use of polyethyleneimine polymer in cell culture as attachment factor and lipofection enhancer. BMC Biotechnol 4:23. https://doi. org/10.1186/1472-6750-4-23

40. Rushmore TH, Morton MR, Pickett CB (1991) Activation by oxidative stress and identification of the DNA consensus sequence required for functional activity. J Biol Chem 266:11632-11639

41. Wasserman WW, Fahl WE (1997) Functional antioxidant responsive elements. Proc Natl Acad Sci 94:5361-5366

42. Wang XJ, Hayes JD, Wolf CR (2006) Generation of a stable antioxidant response element-driven reporter gene cell line and its use to show redox-dependent activation of Nrf2 by cancer chemotherapeutic agents. Cancer Res 66:10983-10994. https:// doi.org/10.1158/0008-5472.CAN-06-2298

43. Cerami E, Gao J, Dogrusoz U et al (2012) The cBio cancer genomics portal: an open platform for exploring multidimensional cancer genomics data. Cancer Discov 2:401-404. https:// doi.org/10.1158/2159-8290.CD-12-0095

44. Kimber I, Basketter DA, Butler M et al (2003) Classification of contact allergens according to potency: proposals. Food Chem Toxicol 41:1799-1809

45. Gerberick GF, Ryan CA, Kern PS et al (2005) Compilation of historical local lymph node data for evaluation of skin sensitization alternative methods. Dermatitis 16:157-202

46. Basketter D, Darlenski R, Fluhr JW (2008) Skin irritation and sensitization: mechanisms and new approaches for risk assessment. Skin Pharmacol Physiol 21:191-202. https://doi. org $/ 10.1159 / 000135635$

47. Basketter D, Lea L, Cooper K et al (1999) Threshold for classification as a skin sensitizer in the local lymph node assay: a statistical evaluation. Food Chem Toxicol 37:1167-1174. https:// doi.org/10.1016/S0278-6915(99)00112-X

48. ECHA (2017) Guidance to Regulation (EC) No 1272/2008 on classification, labelling and packaging (CLP) of substances and mixtures. https://echa.europa.eu/documents/10162/23036412/ clp_labelling_en.pdf/89628d94-573a-4024-86cc-0b4052a74d65

49. Roberts DW, Api AM (2018) Chemical applicability domain of the local lymph node assay (LLNA) for skin sensitisation potency. Part 4. Quantitative correlation of LLNA potency with human potency. Regul Toxicol Pharmacol 96:76-84. https://doi. org/10.1016/j.yrtph.2018.04.022

50. Webb RG (1975) Isolating organic water pollutants: XAD resins, urethane foams, solvent extraction. Environ Monit Ser EPA US Environ Prot Agency, Corvallis

51. Wagner M, Oehlmann J (2011) Endocrine disruptors in bottled mineral water: estrogenic activity in the E-Screen. J Steroid Biochem Mol Biol 127:128-135. https://doi.org/10.1016/j.jsbmb 2010.10.007

52. Venugopal R, Jaiswal AK (1998) Nrf2 and Nrf1 in association with Jun proteins regulate antioxidant response element-mediated expression and coordinated induction of genes encoding detoxifying enzymes. Oncogene 17:3145-3156. https://doi.org/10.1038/ sj.onc. 1202237

53. Jeyapaul J, Jaiswal AK (2000) Nrf2 and c-Jun regulation of antioxidant response element (ARE)-mediated expression and induction of $\gamma$-glutamylcysteine synthetase heavy subunit gene. Biochem Pharmacol 59:1433-1439. https://doi.org/10.1016/S0006 -2952(00)00256-2

54. Kurz EU, Cole SPC, Deeley RG (2001) Identification of DNAprotein interactions in the $5^{\prime}$ flanking and $5^{\prime}$ untranslated regions of the human multidrug resistance protein (MRP1) gene: evaluation of a putative antioxidant response element/AP-1 binding site. Biochem Biophys Res Commun 285:981-990. https://doi. org/10.1006/bbrc.2001.5262

55. Venugopal R, Jaiswal AK (1996) Nrf1 and Nrf2 positively and c-Fos and Fra1 negatively regulate the human antioxidant response element-mediated expression of $\mathrm{NAD}(\mathrm{P}) \mathrm{H}$ : quinone oxidoreductase 1 gene. Proc Natl Acad Sci 93:14960-14965

56. Andres E, Sá-Rocha VM, Barrichello C et al (2013) The sensitivity of the KeratinoSens ${ }^{\mathrm{TM}}$ assay to evaluate plant extracts: a pilot study. Toxicol Vitr 27:1220-1225. https://doi.org/10.1016/j. tiv.2013.02.008

57. Settivari RS, Gehen SC, Amado RA et al (2015) Application of the KeratinoSens ${ }^{\mathrm{TM}}$ assay for assessing the skin sensitization potential of agrochemical active ingredients and formulations. Regul Toxicol Pharmacol 72:350-360. https://doi.org/10.1016/j. yrtph.2015.05.006

58. Emter R, Natsch A (2015) A fast Resazurin-based live viability assay is equivalent to the MTT-test in the KeratinoSens assay. Toxicol Vitr 29:688-693. https://doi.org/10.1016/j. tiv.2015.02.003

59. O'Neil M (2006) The Merck index-an encyclopedia of chemicals, drugs, and biologicals. Merck and Co., Inc, Whitehouse Station

Publisher's Note Springer Nature remains neutral with regard to jurisdictional claims in published maps and institutional affiliations. 